\title{
Culture and Pedagogy of MEQs
}

\author{
Junko Winch ${ }^{1}$ \\ ${ }^{1}$ University of Sussex, UK \\ Correspondence: Junko Winch, School of Media, Arts and Humanities, University of Sussex, Falmer, UK.
}

Received: March 24, 2021; Accepted: May 1, 2021; Published: May 5, 2021

\begin{abstract}
It is claimed that MEQ is multidimensional and it is complex to agree on what those dimensions are and how they interrelate. The main objective of this study is to investigate the culture and Pedagogy of MEQs. Using four dimensions of cultural framework, the underlying pedagogies for the MEQ was identified. The results of the literature reviews show that the cultures of the MEQ are individualist, weak uncertainty avoidance and small power distance, which indicates the Western concept. It has also uncovered that MEQs interrelates to the concept of motivation and enjoyment. The recommendation is for university to have a permanent MEQ staff to give staff development opportunity on the MEQ pedagogy and culture to improve their quality assurance and accountability. It is also recommended to create MEQ software which incorporates additional quantitative data such as class attendance rates and other descriptive statistics which describe the class (i.e. minimum, maximum and average) to minimise the bias effect of the teaching staff and students and increase validity and reliability of MEQs. This paper may be of use for MEQ designers, teaching staff, quality assurance staff, student experience staff, HR staff and executive board members.
\end{abstract}

Keywords: British university, culture, higher education, MEQs, motivation

\section{Introduction}

Student Evaluation of Teaching (SET) measures teaching performance in higher educational institutions. Several thousands of research studies regarding SETs (Spooren et al., 2013) have been conducted and SET's multiple dimensions (Marsh, 2007; Ching, 2018) have been claimed. The number of dimensions of SETs has been investigated and the number of dimensions is varied from two (Cohen, 2005; Keeley et al., 2006; Keeley et al., 2010; Shevlin, Banyard, Davies \& Griffiths, 2000) to twelve (Mortelmans \& Spooren, 2009; Spooren, 2010) dimensions.

SET stakeholders include students, staff, politicians, alumni, funding bodies and the general public (Kearns, 1998). Specific example of staff may include teaching staff, SET designers, quality assurance staff, student experience staff, HR staff and executive board members.

With regards to the validity and reliability of SET results, SETs remain a controversial topic in higher educational research hand practice questioning (Ory, 2001). Spooren et al. (2013) also claim that research on SETs have so far failed to provide a clear answer concerning validity of SET. It is imperative to consider "validity, reliability and bias" from students', staff, and University and try to meet those requirements.

Two types of SETs have been identified. The first categorisation is: Institutional SET and Local SET. Institutional SETs refer to the university' standard questionnaires distributed to all schools and departments. In addition to Institutional SETs, the majority of schools/department also conducts Local SETs. Local SETs refer to what each school/department sets.

Another categorisation is the timing of administration of SETs: formative and summative. Summative SETs are usually administered at the end of each term, which the majority of SETs usually administer. On the other hand, formative one is administered in the middle of module or program to improve the summative SETs. The last SETs type is administration procedures of SETs whether it is electronic procedures (i.e. on-line) or paper-and-pencil.

SETs may be summarised in the following three purposes: teaching, academic promotion and institutional accountability. It should be noted that the purposes of SETs often interrelate to stakeholders/participants. For example, institutional accountability interrelates to the stakeholder, university and staff due to the involvement of internal quality assurance process (Johnson, 2000). Teaching and academic promotion interrelates to the stakeholder, teaching staff and HR. It should be noted that the "purpose of SETs" also interrelates "validity, reliability and bias". However, academic promotion also interrelates "validity, reliability and bias" due to validity 
hypothesis (Patrick, 2011) and grading leniency hypothesis (Carrell \& West, 2010). This indicates that the purpose of SETs interrelates to both stakeholders and validity, reliability and bias dimensions.

Despite that SETs have been investigated from various aspects, a gap in the scholarship of SET is identified as SETs has not been discussed from a cultural and pedagogical perspective.

The aim of this paper is to fill the gap and identify the cultures and pedagogies of SETs and provide an overview of literature review of SET cultures. The specific Research Question (RQ) is whether SETs have cultural and pedagogical influences. If they do, what are they and what do they mean? The significance of this paper is investigation of SETs from cultural and pedagogical perspectives, which may also uncover the new characteristics of SETs.

The next section discusses MEQ culture and pedagogies followed by the Methodology, Results, Discussion, Conclusions and Recommendations.

\section{MEQ Culture and Pedagogy}

MEQs in this paper is operationally defined as: 1) the main stakeholders consist of students, staff and university, from which stakeholders accepts all the biasing factors; 2) it focuses on Institutional, formative and on-line types; and 3) we use as Module Evaluation Questionnaires (MEQs) to refer to as SETs, which is commonly used in the British universities along with Module Evaluation Surveys, Student Evaluation Questionnaires or Student Evaluation of Teaching and Learning in the British universities.

It may sound challenging to identify MEQ's culture and pedagogy as MEQ and culture do not seem to have anything conceptually in common. However, previous studies have investigated the culture of language teaching method called Communicative Language Teaching (CLT) and the culture of critical thinking using the underlying pedagogies (Winch, 2019). These studies show that investigating the underlying pedagogies of MEQs is also anticipated to go through the similar procedure. Thus, it is possible to identify cultures of MEQ as the history of MEQs suggests that MEQs is quite new (Otani et al., 2012) Western, Anglophone originated concept (Ting, 2000).

\subsection{Theoretical Framework}

This study uses Hofstede et al. (2010)'s cultural taxonomy as a framework of this paper. Hofstede et al.'s (2010) cultural taxonomy consists of five dimensions but large vs. small power distance; individualism vs. collectivism; strong vs. weak uncertainty avoidance; and long- vs. short-term are used and explained next.

\subsection{Individualist vs. Collectivist and its Underlying Pedagogy}

Individualist and collectivist are defined as 'the interests of the individual prevail over the interests of the group' (Hofstede et al., 2010, p. 91) and 'the interest of the group prevails over the interest of individual' (Hofstede et al., 2010, p. 90), respectively. In this dimension, one-to-one interaction, directness/clarity and enthusiasm are introduced as Individualist underlying pedagogies whereas, one-to-whole group interaction, vagueness and calm/relaxed are considered as Collectivist underlying pedagogies.

\subsection{Different Interaction Style}

There are two types of interactions: one-to-one and one-to whole group. One-to-one interaction is usually a preferred pedagogy in an individualist culture. This interaction has further two types: between students used in pair work; and between a student and a teacher whose example includes tutoring. On the other hand, one-to-whole group interaction is normally a preferred pedagogy in a collectivist culture. This pedagogy can explain when the teacher looks at a class as a whole group. Students who were educated in collectivist culture are usually not comfortable with individualist interaction or visa versa.

\subsection{High-Context (HC) or Low-Context (LC) Culture: Directness; Clarity}

Hall (1976) first introduced the concept of HC and LC and defines 'High-Context (HC) communication as "very little is in the coded, explicit, transmitted part of the message" and "HC cultures tend to use indirect, nonconfrontational, and vague language, relying on the listener's or reader's ability to grasp the meaning from the context" (Hall, 1976, p. 84). In addition, individualist cultures also prefer clarity and reasoned argument (Hammer, 2005; Kaye, 2006).

To contrast, LC communication is defined "low context cultures tend to use a more direct, confrontational, and explicit approach to ensure that the listener receives the message exactly as it was sent" (Hall, 1976, p. 84). In writing, the writer is responsible for direct and explicit constructions of meaning (Charnock, 2010) with emphasis on originality or creativity. This suggests individualist cultures interrelate to weak uncertainty avoidance culture. 
Hofstede et al. (2010) agree on how HC and LC communication are used in collectivist and individualist cultures as follows:

little has to be said or written because most of the information is either in the physical environment or supposed to be known by the persons involved, while very little is in the coded, explicit part of the message. This type of communication is frequent in collectivist culture... A low-context communication is one in which the mass of information is vested in the explicit code, which is typical for individualist culture. Many things that are self-evident in collectivist cultures must be said explicitly in individualist culture (Hofstede, 2005, p. 89).

\subsection{HAP: Enthusiasm}

When people feel pleasant, those from an individualist culture tend to experience enthusiasm, excited and energetic (Tsai et al., 2006; Kuppens, 2007; Elliot et al., 2001), whereas collectivist people experience calm, relaxed and serene.

Enthusiasm is often mentioned in the discussion of the concept of enjoyment, which has two types of human emotional states: high arousal positive states (HAP) and low arousal positive states (LAP) (Tsai et al., 2006). HAP states are associated with "enthusiastic, excited, energetic" (Tsai et al., 2006, p. 290) and 'joy' (Kuppens, 2007), whereas LAP states are associated with "calm, relaxed, serene" (Tsai et al., 2006, p. 290), 'content' (Kuppens, 2007) and 'at ease' (Kuppens, 2007). Therefore, enjoyment is perceived differently by individuals and feeling enjoyment implies feeling excitement and enthusiasm for some, while feeling enjoyment implies feeling relaxed and at ease for others (Kuppens, 2007). The different reactions in feeling enjoyment is claimed to be cultural specific. Tsai et al. (2006) point out that individuals from individualist cultures (e.g. American, British, Australian cultures, etc.) seem to prefer and value HAP (e.g. enthusiastic, excited and energetic) and those from a collectivist cultures (e.g. Chinese and other East Asian cultures) seem to prefer and value LAP (e.g. calm, relaxed and serene).

\subsection{PD and its Underlying Pedagogy}

Power Distance (PD) is defined as "the extent to which the less powerful members of institutions and organisations within a country expect and accept that power is distributed unequally" (Hofstede et al., 2010, p. 61). In teaching context, it is defined as the extent to which students expect and accept that teachers' power unequally. Strong PD can be demonstrated in languages and customs. Languages which have extensive politeness words and social environment (i.e. home, school and workplace) which has clear hierarchy system tend to have strong PD cultures. In this dimension, teacher-centred orientation is introduced as a large power distance underlying pedagogy whereas student-centred orientation is discussed as small power distance underlying pedagogy.

\subsection{Teacher -Centred vs. Student-Centred Orientation}

Teacher-centred class is the class which the teacher takes the initiative in the class. Students are not expected to take the initiative in speaking up in the class and the student will speak up only when the teacher pointed out a certain student. (Hofstede et al., 2010). According to Pithers \& Soden (2000), this concept is related to knowledge transmission model of teaching. The strength of a teacher-centred class may be that all students receive the same educational opportunities equally. A potential weakness may be that it is difficult to meet the individual students' requirements. Pedagogy of teacher-centred class belongs to large power distance educational culture. Pedagogy of student-centred class belongs to small power distance educational. Student-centred class usually refers to a class where students are expected to take the initiative in speaking up in the class and the teacher only plays a role of a facilitator. The strength of a student-centred class is to make students more proactive in learning. However, some students prefer and learn better in teacher-centred class.

\subsection{UA and its Underlying Pedagogy}

Uncertainty avoidance (UA) is defined as, "the extent to which the members of a culture feel threatened by ambiguous or unknown situations" (Hofstede et al., 2010, p. 191). The strong Uncertainty Avoidance Index (UAI) scoring nations try to avoid ambiguous situations wherever possible, whereas weak UAI scoring nations are not concerned with any unknown situations. In this dimension, creativity is introduced as a weak uncertainty avoidance underlying pedagogy whereas control is discussed as a strong uncertainty avoidance underlying pedagogy.

\subsection{Creativity vs. Control}

Creativity vs. control seems to correlate with each other. In teaching, as control is lessened, learners' creativity increases. Preference for one correct answer, error elimination and routinisation are pedagogy for the strong UA culture. The fields of study of mathematics and sciences usually adopt a one correct answer system as a common 
practice all around the world. It might be possible to say that students and teachers studying mathematics are likely to share a strong UA culture compared to students and teachers from other departments such as music and art. On the other hand, creativity and open-ended questions are pedagogy for a weak uncertainty avoidance culture. An emphasis on creativity in teaching and learning means freedom from control or routine.

Pair work, cooperative learning and reciprocal teaching are perceived by students as relatively student-controlled (Marks, 2000) than 'teacher-centred'. Pair work was mentioned in the individualist culture using underlying pedagogy of one-to-one interaction. However, pair work is also used as a underlying pedagogy of small PD, creativity.

\subsection{Long- and Short-Term Orientation and its Underlying Pedagogy}

The keyword for long-term is persistence, perseverance, patience self-discipline (Hofstede et al., 2010). Those who adopt long-term orientation can delay gratification and make sustained efforts toward slow results, whereas those with short-term orientation believe that individual class is unrelated to their future career and are unable to think of their outcome in the long-term. In this dimension, good attendance, autonomy and trait emotions are introduced as a long-term orientation underlying pedagogy whereas absenteeism and state emotions are discussed as short-term orientation underlying pedagogy.

\subsection{Attendance}

Those who adopt short-term orientation expect that effort should produce quick result, which influence students' class attendance. Examples of students' reasons who adopt short-term orientation include class boredom, lack of sleep, a dislike for either the class or the lecturer (Fried, Rodriguez \& McCom, 2001; Kirby \& McElroy, 2003), bad weather (Moore et al., 2003), the time of the day of lecture (Devadoss \& Foltz, 1996), the duration of the lecture time (Devadoss \& Foltz, 1996), the days of the week of the lecture time (Marburger, 2001) and socialisation over study (Kassamig et al., 2017).

\subsection{Autonomy}

It is claimed that students who adhere to a long-term culture tend to become autonomous learners (Bembenutty $\&$ Karabenick, 2004). This suggests that autonomy interrelates to long-term culture. According to psychology studies, motivation links to the following three conditions; 1) autonomy; 2) belonging; and 3) perceived competence (Selingman \& Csikszenmihalyi, 2000; Ryan \& Powelson, 1991). This implies that autonomy is linked to motivation, hence autonomy and long-term culture is indirectly interrelated.

\subsection{Trait Emotions and State Emotions (Concept of Enjoyment)}

The concept of enjoyment has two emotions which relate to long-/short-term culture: trait and state emotions (Goetz et al., 2006). "Trait emotions are built over time" (Lumby, 2011, p. 7) and are experiences of cumulative enjoyment. On the other hand, "state emotions are experience in the present (, and it is) the current enjoyment" (Lumby, 2011, p. 7). According to Blunsdon et al. (2003), "students are more willing to act on their feeling for the moment...enjoyment is experienced at the moment, while learning often occurs over a long period of time and one's appreciation of the learning experience (cognition) might occur at a much later point in time" (Blunsdon et al, 2003, p. 52).

Table 1 below summarises the culture and underlying pedagogies of the four dimensions outlined previously.

Table 1. Summary of culture and underlying pedagogies of four dimensions

\begin{tabular}{llll}
\hline & Culture & Pedagogy & Motivation/Enjoyment \\
\hline Power distance (PD) & Small PD & $\begin{array}{l}\text { Student-centred (pair } \\
\text { work) }\end{array}$ & $\begin{array}{l}\text { motivation (sense of belonging) and } \\
\text { participation }\end{array}$ \\
& Large PD & Teacher-centred & \\
\hline $\begin{array}{l}\text { Uncertainty Avoidance } \\
\text { (UA) }\end{array}$ & Weak UA & $\begin{array}{l}\text { Creativity } \\
\text { Control }\end{array}$ & \\
\hline $\begin{array}{l}\text { Individualist vs. } \\
\text { Collectivist }\end{array}$ & Strong UA & Individualist & $\begin{array}{l}\text { One-to-one interaction } \\
\text { (pair work) } \\
\text { LC culture (directness }\end{array}$ \\
\hline
\end{tabular}




\begin{tabular}{|c|c|c|c|}
\hline & Collectivist & $\begin{array}{l}\text { and clarity) } \\
\text { HAP (enthusiasm) } \\
\text { One-to-whole interaction } \\
\text { HC culture (vagueness) } \\
\text { LAP (calm/relaxed) }\end{array}$ & $\begin{array}{l}\text { motivation } \\
\text { enjoyment }\end{array}$ \\
\hline $\begin{array}{l}\text { Long- vs. Short-term } \\
\text { orientation }\end{array}$ & $\begin{array}{l}\text { Long-term } \\
\text { Short-term }\end{array}$ & $\begin{array}{l}\text { Good attendance } \\
\text { Autonomy (motivation) } \\
\text { Trait emotions } \\
\text { Absenteeism } \\
\text { State emotions } \\
\end{array}$ & $\begin{array}{r}\text { motivation } \\
\text { enjoyment } \\
\text { enjoyment }\end{array}$ \\
\hline
\end{tabular}

\section{Methodology}

\subsection{Materials}

The pedagogies regarding the MEQ's individualist-collectivist, power distance, uncertainty avoidance and longor short-term, motivation and enjoyment were retrieved from a total of published 56 publications [50 journal articles and 6 books] from the field of Business Studies and Management, Education, language, Linguistics, Psychology and Social Studies. The dates for these studies range between 1968 and 2019. This study does not involve human participants.

\subsection{Methods}

The literature review involved database retrievals and searches defined by a specific topic (Rother, 2007) through computer keyword search through journals in the framework. This allowed retrieving MEQ culture pedagogies to be identified. Keywords used for MEQ culture pedagogies were: one-to-one interaction, pair work, high-/lowcontext culture, creativity/originality, clarity, direct/indirect, student-centred, participation, attendance, rhetorical strategies. In a similar method, keywords search for motivation and enjoyment were also conducted and identified. The following keywords were used for this study: sense of belonging, autonomy, perceived competence, trait emotions, state emotions, HAP and LAP. The literature includes both empirical studies, conceptual, theoretical and review studies which were fully read. All the qualified chosen journals went through content analysis consistently and scrutinised for inclusion.

\subsection{Procedure}

The procedure involved a three-tier investigation. The first stage was investigated by using 62 journals and books which include suitable statements matching with keywords in the four dimensions of culture. The results were organised into each dimension (individualist-collectivist, power distance, uncertainty avoidance and long- and short-dimensions) using qualitative analysis method by Miles \& Huberman (1994) and how they are interrelated was determined. In the second stage, how these four dimensions are interrelated with pedagogies of motivation and enjoyment were synthesised and incorporated by the keywords. In the last stage, the aim of this study mentioned in Introduction (i.e. to identify the pedagogies of MEQ cultures on four cultural dimensions and how motivation and enjoyment they are interrelated) were answered.

\section{Results and Discussion}

MEQ adopts the following dimensions: small PD, weak UA and individualism. These are justified and supported with evidence of MEQ's underlying pedagogies.

\subsection{Weak UA: Creativity}

MEQs have a weak UA culture whose underlying pedagogy is creativity. Early research findings suggest that students sometimes interpret a teacher's 'creativeness' as a positive character (Costin et al., 1971), which demonstrates that MEQ culture has been weak UA.

\subsection{Long-vs. Short-Term Culture: Attendance, Autonomy, Trait/State Emotions}

This dimension of MEQs may be difficult to conclude whether long- or short-term orientation. However, this dimension relates to students' attendance, autonomy and trait/state emotions which are the underlying pedagogy of this dimension. This dimension also interrelates to the concept of enjoyment and motivation.

\subsection{Autonomy}

When we discuss autonomy, it is important to refer to psychology studies related to motivation. According to Ryan \& Powelson (1991), persons in the following three conditions (Ryan \& Powelson, 1991); 1) autonomy; 2) a sense 
of belonging and 3) perceived competence) are intrinsically motivated (Selingman \& Csikszenmihalyi, 2000). In other words, autonomy is one of motivational factors. To keep this in mind, Bembenutty \& Karabenick (2004) claim that students who adhere to long-term culture tend to become autonomous learners. Bembenutty \& Karabenick (2004) claim suggests that autonomy interrelates to long-term culture. However, there are students who adhere to short-term culture who do not attend classes for the following reasons: class boredom, lack of sleep, a dislike for either the class or the lecturer (Fried, Rodriguez \& McCom, 2001; Kirby \& McElroy, 2003), bad weather (Moore et al., 2003), the time of the day of the lecture (Devadoss \& Foltz, 1996), the duration of the lecture time (Devadoss \& Foltz, 1996), the days of the week of the lecture (Marburger, 2001) and socialisation over study (Kassarnig et al., 2017).

\subsection{Attendance and Trait/State Emotions (Concept of Enjoyment)}

Attendance and trait/state emotions are usually discussed together as they are often interrelated. Firstly, how MEQs and attendance relates is explained using following quotes:

Taking a university course would typically require the student to attend class every week, which corresponds to repeated service encounters that are critical to later evaluation (Solomon et al., 1985); Within the concept of service marketing, these repeated service encounters (which in this case are the repeated classroom encounters) correspond to the experience qualities that students perceive when taking the course (Ching, 2018).

Another research results claims that the higher the class attendance rate, the higher SETs (Ting, 2000), which shows a link between MEQs and attendance.

Secondly, MEQs also interrelate to the concept of enjoyment, specifically, trait/state emotions. Trait emotions are long-term orientation and state emotions are short-term orientation. Whether MEQ culture is a long- or short-term orientation appears difficult to conclude as some scholars claim that it is difficult to determine whether a single class or the collective sum of the semester's learning encounters contribute to the SET rating (Ching, 2018), which is also discussed in the concept of enjoyment whether enjoyment is a accumulative or present experience. Curran \& Rosen (2006) also agree that it can be difficult to know whether the resulting SET ratings are based on an overall experience of the course or just on one single event that made a lasting impression.

\subsection{Small Power Distance: Student-Centred}

MEQs have a small PD cultures whose underlying pedagogy is student-centred (pair work). Baumeister \& Leary (1995) claim that student-centred may give an addictive effect to people who perceive an environment as caring, and also fulfil their need to belong. This claim suggests that small PD and a sense of belonging are interrelated. A sense of belonging is one of motivational factor to achieve motivation (Ryan \& Powelson, 1991), which implies that student-centred (small PD) also interrelates to motivation.

Another close link between a sense of belonging and participation is demonstrated as follows:

The more students feel a sense of belonging, the more participation increases (Watkins, 2005); Participation is essential for the students' sense of belonging to be realised (Finn, 1989).

The above statements suggest that participation also interrelates to PD, which indicates a close link to the concept of motivation.

\subsection{Individualist: One-to-one Interaction; Clarity; Enthusiasm}

MEQs have individualist cultures whose underlying pedagogies are one-to-one interaction (pair work), LC culture (direct/clear) and enthusiasm.

\subsection{One-to-one Interaction, Pair Work}

Although pair work was previously mentioned as an underlying pedagogy of student-centred orientation in the small PD culture, pair work also provides one-to-one interaction and is also used as an underlying pedagogy of individualist. This implies that pair work has a close link to two dimensions between Individualist and PD dimension.

\subsection{Clarity and Enthusiasm}

Clarity and enthusiasm has been included as pedagogical constructs of SETs analysis conducted by previous researchers (Mehrabian, 1968; Feldman, 1976; Hildebrand, 1973; Hildebrand et al., 1971; Marsh, 1982, 1987; Marsh \& Dunkin, 1997; Richardson, 2005) from 1968 to 2005, which indicates that MEQs value these pedagogical constructs and have individualist characteristics.

Table 2 below summarise the MEQ's culture and underlying pedagogy which was outlined above. 
Table 2. Summary of MEQ culture and pedagogy.

\begin{tabular}{lllll}
\hline & Culture & Pedagogy & Motivation/enjoyment \\
\hline $\begin{array}{l}\text { Power distance } \\
\text { (PD) }\end{array}$ & Small PD & $\begin{array}{l}\text { Student-centred } \\
\text { work) }\end{array}$ & (pair & $\begin{array}{l}\text { motivation (sense of belonging } \\
\text { Creativity }\end{array}$ \\
\hline $\begin{array}{l}\text { Uncertainty } \\
\text { Avoidance (UA) }\end{array}$ & Weak UA & $\begin{array}{l}\text { One-to-one interaction, motivation } \\
\text { (pair work, also link to } \\
\text { small PD) } \\
\text { LC culture (directness and } \\
\text { clarity) } \\
\text { Collectivist }\end{array}$ & Individualist & \\
& & HAP (enthusiasm) & motivation \\
\hline $\begin{array}{l}\text { Long-vs. Short- } \\
\text { term }\end{array}$ & $\begin{array}{l}\text { Cannot be determine as } \\
\text { either long- or short- } \\
\text { term }\end{array}$ & & \\
\hline
\end{tabular}

\section{Conclusions}

The purpose of this study is to identify the culture and pedagogy of MEQ. The specific RQ of this study asked whether MEQs have cultural and pedagogical influences. To answer the cultural influence, MEQs has a combination of individualist, small PD and weak UA cultures, all of which are interrelated.

To answer the pedagogical influences, the pedagogy of small PD culture is student-centred, which interrelates to a sense of belonging, motivation, participation and attendance. The pedagogy of long-/short-term culture relates to autonomy and participation, which also interrelates to the concept of motivation, attendance and trait/emotions. The pedagogy of individualist culture is one-to-one interaction, which is represented with pair work. Individualist dimension has quite keywords including 'enthusiastic', 'direct', 'clarity' and 'creativity/originality', which interrelates uncertainty avoidance culture, power distance culture, concept of motivation, concept of enjoyment, $\mathrm{HC} / \mathrm{LC}$ context culture and HAP/LAP.

In addition to three cultures and their underlying pedagogies, MEQs also interrelates to a sense of belonging and autonomy which are part of the concepts of motivation. MEQs' trait/state emotions and HAP are from the concepts of enjoyment.

\section{Recommendations and Further Study}

As MEQs and academic promotions are seemingly related and MEQs are used as evidence case for teaching staff's academic promotion, it is possible to say that getting familiar with MEQ pedagogies, MEQ culture, concept of motivation and enjoyment will enable better MEQ results. Hence, it is recommended for the university to offer their teaching staff development opportunities on MEQ pedagogy and culture to improve their quality assurance, student experience and accountability purposes.

The second recommendation is for University to have a permanent MEQ team which consists of MEQ designers, quality assurance staff, student experience staff, HR staff, students and executive board members so that they keep informed on the most current MEQ literature which may change subject to the demand of the time. Carefully developed MEQs have the potential to offer valuable insight for students, faculty members and university.

As for suggested further study, it is hoped to develop MEQ software which present incorporating quantitative data such as the class attendance rate and other descriptive statistics which describe the class (i.e. minimum, maximum and average) to minimise the bias effect by teaching staff and students and increase validity and reliability of MEQs.

\section{References}

Baumeister, R. F., \& Leary, M. R. (1995). The need to belong: Desire for interpersonal attachments as a fundamental human motivation. Psychological Bulletin, 117, 497-529.

Bembenutty, H. \& Karabenick, S. A. (2004). Inherent association between academic delay of gratification, future time perspective, and self-regulated learning, Educational Psychology Review, 16(1), 35-57. https://doi.org/10.1023/B:EDPR.0000012344.34008.5c

Blunsdon, B. Reed, K., \& McNeil, N. (2003). Experiential Learning in Social Science Theory: An investigation of 
the relationship between student enjoyment and learning. Journal of Further and Higher Education, 22(1), 93-56. https://doi.org/10.1080/0729436032000056544

Carrell, S. E., \& West, J. E. (2010). Does professor quality matter? Evidence from random assignment of students to professors. Journal of Political Economy, 118, 409-432.

Charnock, K. (2010). The right to reticence. Teaching in Higher Education, 15(5), 543-552. https://doi.org/10.1080/13562517.2010.491907

Ching, G. (2018). A literature review on the student evaluation of teaching - An examination of the search, experience, and credence qualities of SET, Higher Education Evaluation and Development, 12(2), 63-74. https://doi.org/10.1108/HEED-04-2018-000

Cohen, E. H. (2005). Student evaluations of course and teacher: Factor analysis and SSA approaches. Assessment \& Evaluation in Higher Education, 30, 123-136. https://doi.org/10.1080/026029304200026423

Costin, F., Greenough, W. T., \& Menges, R. J. (1971). Student ratings of college teaching: reliability, validity, and usefulness, Review of Educational Research, 41(5), 511-535.

Curran, J. M., \& Rosen, D. E. (2006). Student attitudes toward college courses: an examination of influences and intentions. Journal of Marketing Education, 28(2), 135-148. https://doi.org/10.1177/0273475306288401

Devadoss, S., \& Foltz, J. (1996). Evaluation of factors influencing student class attendance and performance. American Journal of Agriculture Economics, 78, 499-507.

Elliot, A., Chirkov, V. I., Kim, Y., \& Sheldon, K. (2001). A cross-cultural analysis of avoidance (relative to approach) personal goals. Psychological Science, 12(6), 505-510.

Feldman, K. A. (1976). The superior college teacher from the students' view, Research in Higher Education, 5(3), 243-288. https://doi.org/10.1007/BF00991967

Finn, J. D. (1989). Withdrawing from School. Review of Educational Research, 59(2), 117-142. for Teaching and Learning, 87, 3-15. https://doi.org/10.1002/tl.234

Fried, P., Rodriguez, F., \& McComb, J. (2001). Why students do and do not attend classes: myths and realities. Coll. Teach, 49(4), 124-133.

Goetz, T., Nathan, C., Hall, Anne, C., Frenzel, A., \& Pekrun, R. (2006). A hierarchical conceptualization of enjoyment in students. Learning and Instruction, 16, 323-338. https://doi.org/10.1016/j.learninstruc.2006.07.004

Hall, E. T. (1976). Beyond Culture. New York: Anchor Books.

Hammer, M. R. (2005). The Intercultural Conflict Style inventory: A conceptual framework and measure of intercultural conflict resolution approaches. International Journal of Intercultural Relations, 29(6), 675-695. https://doi.org/10.1016/j.ijintrel.2005.08.010

Hildebrand, M. (1973). The character and skills of the effective professor, The Journal of Higher Education, 44(1), 41-50.

Hildebrand, M., Wilson, R. C., \& Dienst, E. R. (1971). Evaluating University Teaching, Center for Research and Development in Higher Education, Berkeley, CA.

Hofstede, G., \& Hofstede, G. J. (2005). Cultures and organizations: Software of the mind, Revised and expanded. (2nd ed.). New York, NY: McGraw-Hill Book Company.

Hofstede, G., Hofstede, G. J., \& Minkov, M. (2010). Cultures and Organizations - Software of the mind. New York, NY: McGraw-Hill Book Company.

Johnson, R. (2000). The authority of the student evaluation questionnaire. Teaching in Higher Education, 5, 419434. http://doi.org/10.1080/713699176

Kassarnig, V., Bjerre-Nielsen, A., Mones, E., Lehmann, S., \& Lassen, D. (2017). Class attendance, peer similarity and academic performance in a large field study, Plos One, 8, 1-15.

Kaye, D. L. (2006). International students as (un)bounded sojourners: Emergent articulations of culture and identity through intercultural communication. Carbondale, IL: Southern Illinois University Press.

Kearns, K. (1998). Institutional Accountability in Higher Education: A Strategic Approach. Public Productivity \& Management Review, 22(2), 140-156. 
Keeley, J., Furr, R. M., \& Buskist, W. (2010). Differentiating psychology students' perceptions of teachers using the Teacher Behavior Checklist. Teaching of Psychology, 37, 16-20. https://doi.org/10.1080/00986280903426282

Keeley, J., Smith, D., \& Buskist, W. (2006). The Teacher Behaviors Checklist: Factor

Kirby, A., \& McElroy, B. (2003). The effect of attendance on grade for first year economics students in University College Cork. Economic and Social Review, 34, 311-326.

Kuppens, P. (2007). Individual differences in the relationship between pleasure and arousal, Journal of Research in Personality, 42, 1053-1059. https://doi.org/10.1016/j.jrp.2007.10.007

Lumby, J. (2011). Enjoyment and learning: Policy and secondary school learners' experience in England. British Educational Research Journal, 37(2), 247-264. https://doi.org/10.1080/01411920903540680.

Marburger, D. R. (2001). Absenteeism and undergraduate exam performance. Journal of Economic Education, 32, 99-109.

Marks, H. M. (2000). Student engagement in instructional activity: Patterns in the elementary, middle and high school years. American Educational Research Journal, 37, 153-184.

Marsh, H. W. (1982). SEEQ: a reliable, valid, and useful instrument for collecting students' evaluations of university teaching, British Journal of Educational Psychology, 52(1), 77-95. https://doi.org/10.1111/j.20448279.1982.tb02505.x

Marsh, H. W. (1987). Students' evaluations of university teaching: research findings, methodological issues, and directions for future research, International Journal of Educational Research, 11(3), 253-388. https://doi.org/10.1016/0883-0355(87)90001-2

Marsh, H. W. (2007). Students' evaluations of university teaching: dimensionality, reliability, validity, potential biases and usefulness, in Perry, R. P. \& Smart, J. C. (Eds), The Scholarship of Teaching and Learning in Higher Education: An Evidence-Based Perspective, Springer, Dordrecht, 319-383.

Marsh, H. W., \& Dunkin, M. J. (1997). "Students' evaluations of university teaching: A multidimensional perspective", in Perry, R. P. and Smart, J. C. (Eds), Effective Teaching in Higher Education: Research and Practice, Agathon, New York, NY, 241-320.

Mehrabian, A. (1968), Some referents and measures of nonverbal behavior, Behavior Research Methods \& Instrumentation, 1(6), 203-207. https://doi.org/10.3758/BF03208096

Miles, M. B., \& Huberman, A. M. (1994). Qualitative Data Analysis, London, Sage publications.

Moore, R., Jensen, J. M., Hatch, J., Duranczyk, I., Staats, S., \& Koch, L. (2003). Showing up: The importance of class attendance for academic success in introductory science course. American Biology Teacher, 65, 325329.

Mortelmans, D., \& Spooren, P. (2009). A revalidation of the SET37-questionnaire for student evaluations of teaching. Educational Studies, 35, 547-552. https://doi.org/10.1080/03055690902880299

Ory, J. C. (2001). Faculty thoughts and concerns about student ratings. New Directions

Otani, K., Kim, B. J., \& Cho, J. I. (2012). Student evaluation of teaching (SET) in higher education: how to use SET more effectively and efficiently in public affairs education, Journal of Public Affairs Education, 18(3), 531-544.

Patrick, C. L. (2011). Student evaluations of teaching: effects of the Big Five personality traits, grades and the validity hypothesis. Assessment \& Evaluation in Higher Education, 36(2), 239-249. https://doi.org/10.1080/02602930903308258

Pithers, R. T., \& Soden, R. (2000). Critical thinking in education: a review. Educational Research, 42(3), 237-249. https://doi.org/10.1080/001318800440579

Richardson, J. T. E. (2005). Instruments for obtaining student feedback: a review of the literature, Assessment \& Evaluation in Higher Education, 30(4), 387-415. https://doi.org/10.1080/02602930500099193

Rother, E. T. (2007). Systematic literature review - narrative review, Acta Paulista de Enfermagem, 20(2), vii-viii.

Ryan, R. M., \& Powelson, C. L. (1991). Autonomy and relatedness as fundamental to motivation and education. Journal of Learning Disabilities, 19, 500-503.

Selingman, M. E. P., \& Csikszenmihalyi, M. (2000). Positive Psychology: An Introduction, American Psychologist, 
55(1), 5-14. https://doi.org/10.1037//0003-066X.55.1.5

Shevlin, M., Banyard, P., Davies, M., \& Griffiths, M. (2000). The validity of student evaluation in higher education: Love me, love my lectures? Assessment \& Evaluation in Higher Education, 25, 397-405. https://doi.org/10.1080/713611436

Solomon, M. R., Surprenant, C. F., Czepiel, J. A., \& Gutman, E. G. (1985). A role theory perspective on dyadic interactions: the service encounter. Journal of Marketing, 49(1), 99-111.

Spooren, P. (2010). On the credibility of the judge. A cross-classified multilevel analysis on student evaluations of teaching. Studies in Educational Evaluation, 36, 121-131. https://doi.org/10.1016/j.stueduc.2011.02.001

Spooren, P., Brockx, B., \& Mortelmans, D. (2013). On the validity of student evaluation of teaching: The state of the art. Review of Educational Research, 83(4), 598-642. https://doi.org/10.3102/0034654313496870

Ting, K. (2000). A multilevel perspective on student ratings of instruction: Lessons from the Chinese experience. Research in Higher Education, 41, 637-661. https://doi.org/10.1023/A:1007075516271

Tsai, J. L., Knutson, B., \& Fung, H. (2006). Cultural Variation in Affect Valuation. Personality Processes and Individual Differences, 90(2), 288-307. https://doi.org/10.1037/0022-3514.90.2.288

Watkins, C. (2005). Classrooms as learning communities: a review of research. London Review of Education, 3(1), 47-64.

Winch, J. (2019). Does Communicative Language Teaching Help Develop Students' Competence in Thinking Critically. Journal of Language and Education, 5(2), 112-122. https://doi.org/10.17323/jle.2019.8486

\section{Copyrights}

Copyright for this article is retained by the author(s), with first publication rights granted to the journal.

This is an open-access article distributed under the terms and conditions of the Creative Commons Attribution license (http://creativecommons.org/licenses/by/4.0/). 